\title{
Is transluminal coronary angioplasty mandatory after successful thrombolysis?
}

\section{Quantitative coronary angiographic study}

\author{
$P$ W SERRUYS, W WIJNS, M VAN DEN BRAND, V RIBEIRO, P FIORETTI, M L SIMOONS, \\ C J KOOIJMAN, J H C REIBER, P G HUGENHOLTZ
}

With the technical assistance of Susan Veldhof and Ingrid Broeders
From the Thoraxcenter, Erasmus University and University Hospital Dijkzigt, Rotterdam, the Netherlands

SUMMARY Percutaneous transluminal coronary angioplasty has been advocated as a mandatory procedure to prevent reocclusion after successful thrombolysis in acute myocardial infarction. This study describes our experience with both procedures over a 12 month period. Out of 105 patients catheterised in the acute phase of myocardial infarction, 64 were recanalised with 250000 units of streptokinase, while in 25 patients recanalisation could not be achieved. In the remaining 16 , the infarct related vessel was patent at the time of the procedure. Eighteen of the 78 patients who had a patent infarct related vessel at the end of the recanalisation procedure underwent transluminal angioplasty immediately afterwards. Post lysis angiograms were analysed quantitatively with a computerised measurement system. The contours of the relevant arterial segments were detected automatically. Reference diameter, minimal obstruction diameter, length of the lesions, and percentage diameter stenosis were averaged from multiple views.

In $31 \%$ of our patients a diameter stenosis of less than $50 \%$ was found whereas one of $70 \%$ or more was seen in only $19 \%$. Eleven stenotic lesions, recanalised at the acute stage, reoccluded in the short term, and in the long term eight other patients sustained a reinfarction in the same myocardial territory. Seventeen of these 19 recanalised lesions had a diameter stenosis of $58 \%$ or more. In view of these results, we felt justified in combining recanalisation and angioplasty in 18 patients selected from the most recent admissions. In these patients, the mean diameter stenosis decreased from 59\% to $30 \%$ and mean pressure gradient from 41 to $8 \mathrm{mmHg}$. Late follow up showed reocclusion in one case. Though percutaneous transluminal coronary angioplasty does not seem to be mandatory at the acute stage in the majority of patients, it is feasible to undertake in one sitting and seems to prevent reocclusion in patients selected on the basis of quantitative angiographic criteria.

Salvage of ischaemic but still viable myocardium around areas of myocardial infarction is currently a topic of much clinical interest. The removal of obstruction of the nutrient artery by intracoronary thrombolysis in the first hours after the onset of myocardial infarction ${ }^{1-3}$ has proved a new approach which is undergoing randomised trials in our own and other institutions. ${ }^{4-6}$ Since there is often residual stenosis, additional transluminal angioplasty and/or coronary artery bypass grafting have been advocated as a mandatory procedure after successful recanalisation. It has been argued that a severe residual stenosis in the area of the previous occlusion might cause reocclusion over the ensuing days. ${ }^{7-11}$ In order to eluci-

Accepted for publication 12 May 1983 date this question, quantitative angiographic analysis was applied to recanalised vessels of 78 patients who had an open infarct related vessel at the end of the procedure. Tentative answers were formulated on three questions: How severe are the residual lesions after 'successful' thrombolysis? Is it possible to identify those lesions that are liable to reocclude in the short term? In order to prevent reocclusion after initial successful recanalisation, is transluminal angioplasty a mandatory procedure?

\section{Patients and methods}

Between September 1980 and December 1982, coronary recanalisation was attempted in 105 patients. Different procedures were used since our first experi- 
ence with intracoronary thrombolysis in September 1980. They have been described elsewhere. ${ }^{4}$ In the current randomised trial, patients below 65 years of age were selected, without a history of haemorrhagic diathesis or previous cerebrovascular accident. On admission all patients suffered from chest pain lasting less than four hours. The electrocardiogram showed typical myocardial infarction with ST elevation. The combination of hypotension (systolic pressure below $90 \mathrm{mmHg}$ ) and sinus tachycardia (heart rate over 100 beats/minute) led to temporary exclusion, but if the haemodynamic condition of the patient returned to normal quickly, he was still able to be included in the study. Informed consent was obtained from all patients assigned to thrombolytic treatment. Immediately after admission, an infusion of glyceryl trinitrate was started and as soon as possible the patient was transferred to the catheterisation laboratory. Prophylactic lignocaine was given intravenously in a dose of $2 \mathrm{mg} / \mathrm{min}$.

\section{TECHNIQUE OF INTRACORONARY STREPTOLYSIS}

After puncturing the femoral vein and artery a pacemaker catheter was positioned in the right ventricle. Heparin, $50 \mathrm{mg}$, was administered intravenously as well as $250 \mathrm{mg}$ acetosalicylic acid and $100 \mathrm{mg}$ diadresone $F^{R}$. A non-ionic contrast agent (Amipaque) was used as a contrast medium for coronary angiography of the artery suspected to be thrombosed; subsequently $0.2 \mathrm{mg}$ nifedipine was injected into the occluded artery over a period of three minutes, while the aortic pressure was monitored. Coronary angiography was then repeated to evaluate the spasmolytic effect on the coronary occlusion. Intracoronary perfusion with streptokinase was carried out at a rate of 4000 units a minute to a maximum of 250000 units of streptokinase, diluted in $500 \mathrm{ml}$ physiological solution at a flow rate of $8 \mathrm{ml}$ per minute. Coronary angiograms were repeated every 15 minutes until the chest pain disappeared. The appearance of ventricular extrasystoles or any conduction disturbance was an additional reason to revisualise the artery. If there were no signs of recanalisation, an attempt was made to administer streptokinase locally in a higher concentration by passing a thin catheter (French 2 or 3 ) with a radiopaque tip through the Judkins catheter (French 8). After the procedure, selective coronary angiography in multiple projections was performed with an ionic contrast medium (urografin $76 \%$ ).

All arteriograms were recorded on Kodak $35 \mathrm{~mm}$ cinefilm at the rate of 25 frames/s. The stenotic areas were filmed in two different projections in stenoses of the right and left circumflex coronary artery and in at least three projections, including one craniocaudal, in stenoses of the left anterior descending artery.
TECHNIQUE OF PERCUTANEOUS TRANSLUMINAL CORONARY ANGIOPLASTY

In 18 patients an attempt was made to dilate the residual stenosis. In 16 patients, percutaneous transluminal coronary angioplasty was perfomed in the same session, 20 to 60 minutes after the end of streptokinase infusion. In two other patients, percutaneous transluminal coronary angioplasty was perfomed in a second session, respectively eight hours and 12 days later. Via a 9F, $16 \mathrm{~cm}$ long introducing sheath, a guiding catheter was directed into the stenotic area under fluoroscopic and pressure control. In four of the 18 successfully treated cases, we used a balloon catheter with an outer diameter of $3.7 \mathrm{~mm}$, in the 14 other patients its outer diameter was $3 \mathrm{~mm}$. The mean pressure gradient across the stenotic lesion was computed on line after 20 seconds of data acquisition. Two to nine (mean 4.5 ; SD 2.3 ) balloon inflations were performed for a period of 10 to 70 seconds (mean 49; SD 12) at a pressure of 4 to $8 \mathrm{bar}$ (mean 6; SD 1). After the dilatation procedure the sheath was left in place for the next 24 hours, while the patients were monitored in the coronary care unit.

All patients received heparin (20 $000 \mathrm{U} / 24 \mathrm{~h})$ followed by oral coumarin until discharge from the hospital. Anticoagulants were continued after discharge in patients with left ventricular aneurysm or recognised mural thrombus in the left ventricle. In addition, nifedipine, $10 \mathrm{mg}$ every four hours, was given for two days in patients treated with streptokinase. ${ }^{12}$

\section{QUANTITATIVE ANGIOGRAPHIC ANALYSIS}

The quantitative analysis of selected coronary segments was carried out with the help of a computer based coronary angiography analysis system, which has been described extensively elsewhere. ${ }^{13-15}$ To analyse a selected $35 \mathrm{~mm}$ cineframe, the film was placed on a specially constructed cine video converter. An optically magnified portion of the cineframe was converted into video format with a high resolution video camera and displayed on a video monitor; routinely, an optical magnification factor of 2 is used. The computerised analysis of a selected coronary segment required the manual definition of a number of centre positions within the segment by means of a writing tablet. Regions of interest encompassing the arterial segment were digitised and stored in the PDP 11/44 minicomputer. Subsequently, the contour positions of the segment were detected automatically on the basis of first and second derivative criteria. From these contour positions the diameter function of the segment was computed. The diameter values are given in absolute values ( $\mathrm{mm}$ ), since the contrast catheter was used as a scaling device (Fig. 1a).

As a next step the computer algorithm determined 

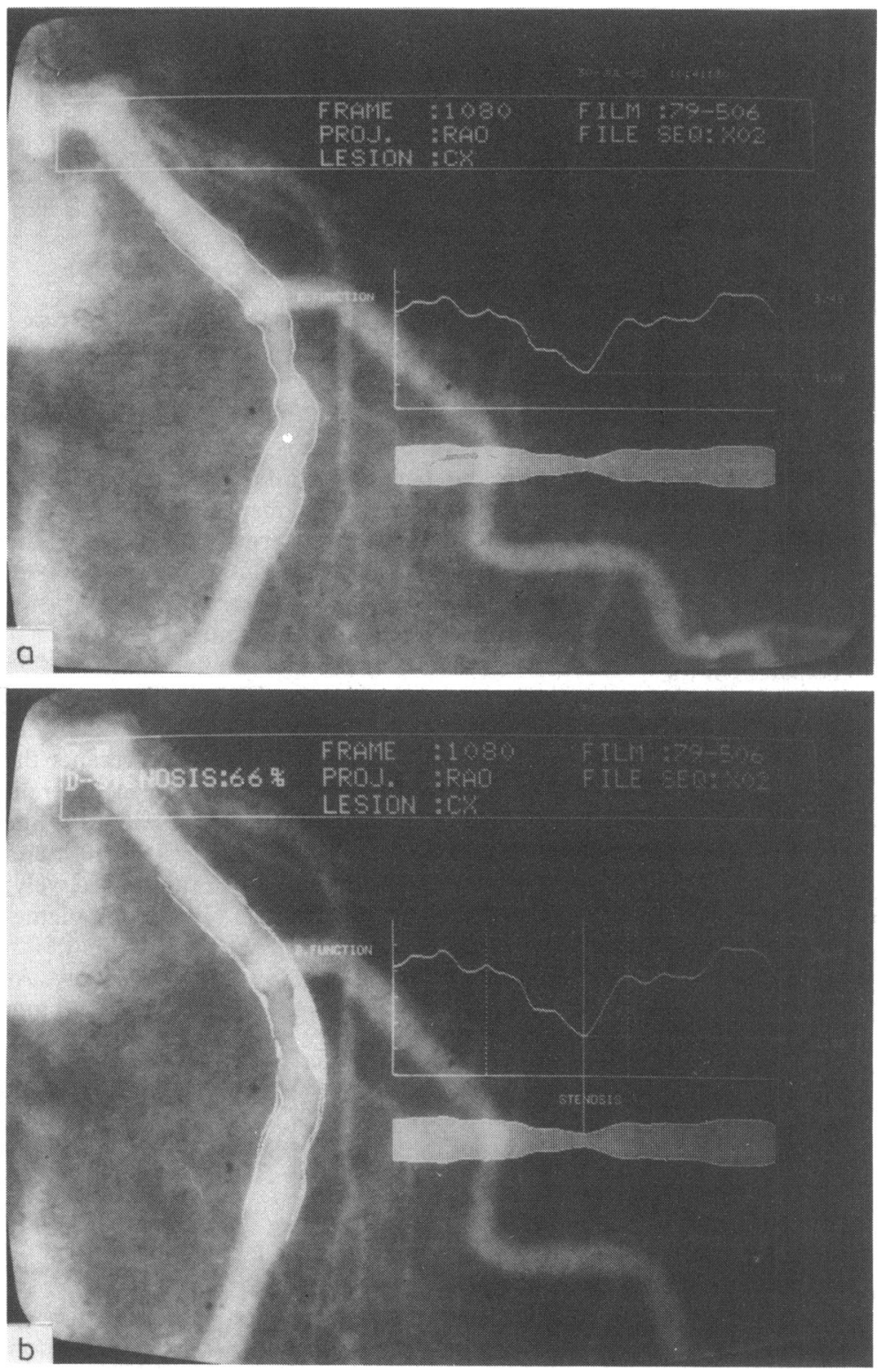

Fig. 1 (a) Contours for obtuse marginal branch superimposed on the original video image. From the detected contours the diameter function is determined by computing the shortest distance between left and right contour positions. The calibrated diameter values in $\mathrm{mm}$ are plotted along the ordinate and the centreline positions from the proximal to the distal part along the abcissa. (b) For the lesion in Fig. 1(a) the normal size of the artery has been estimated from the normal proximal and distal diameter values. The marked area is a measure of the atherosclerotic plaque. An interpolated percentage diameter stenosis of 66 results. the position of the obstruction by searching for the minimal diameter value in the diameter function This position could be changed interactively by the user, if more than one focal obstruction was to be processed within the analysed segment. The extent of the obstruction was computed from the diameter function on the basis of curvature analysis and expressed in $\mathrm{mm}$.

The severity of a coronary obstruction was determined by the interpolated percentage diameter stenosis measurement. ${ }^{15}$ The basic idea behind this technique is the computer estimation of the original contour positions over the obstructive region (assuming there was no coronary disease present) based on the course of the proximal and distal centreline segments and on the diameter function. The resulting reference contours of the arterial segment of Fig. la are shown in Fig. 1b, with the difference in area between this boundary and the detected contours marked over the obstructive lesion; this area is a measure of the atherosclerotic plaque. The interpolated percentage diameter stenosis was then computed by comparing the minimal diameter value at the obstruction 
with the corresponding value of the reference contour at this position. For Fig. $1 \mathrm{~b}$ an interpolated percentage diameter stenosis of $50 \%$ results. It is clear that the computed reference contour can only be a reasonable approximation of the non-diseased segment if the proximal and distal segments are essentially free of atherosclerosis. Even if this is not true this method may still be the method of choice in the majority of cases for the determination of percentage diameter stenosis, because it is minimally influenced by any observer error.

\section{Results}

\section{PATENCY OF INFARCT RELATED VESSEL, ACUTE AND CHRONIC STAGE}

The angiographic findings at the beginning and at the end of the recanalisation procedure are given in Fig. 2. In 64 patients, thrombolysis was successful and after recanalisation transluminal angioplasty was performed in 18 of these 64 patients. In 16 other patients the infarct related vessel was found to be patent at the first coronary angiogram. In two of the 16 cases, occlusion of an initially patent artery occurred during the procedure. Thus, 78 infarct related vessels were patent at the end of the catheterisation procedure. In 25 patients we did not succeed in recanalising the thrombosed arteries.

Fifty seven patients, excluding those who had undergone percutaneous transluminal coronary angioplasty in the acute phase, agreed to have further angiograms two weeks later (Fig. 3). In 41 patients, the infarct related vessel was still patent. Five lesions which had remained occluded at the acute stage were found to be recanalised at this point; in seven other patients the coronary arteries which had been successfully recanalised at the acute stage were now found to be reoccluded. This observation suggests a reocclusion rate of $17 \%$ two weeks after recanalisation.

Moreover, in the long term follow up (mean 8.3 months) eight other patients sustained a reinfarction in the same myocardial territory, which was documented with the electrocardiogram and cardiac

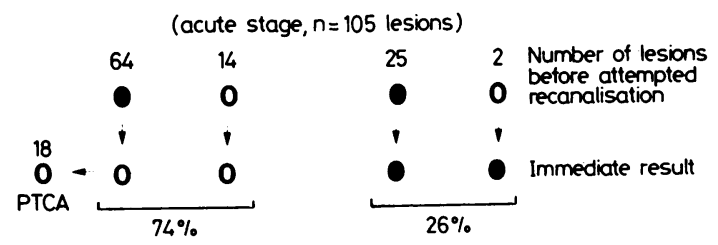

Fig. 2 Results of attempts at intracoronary thrombolysis in 105 patients. The upper line represents the initial angiographic finding, the lower line the state of the infarct related vessel at the end of the procedure. $\bullet=$ occluded vessel; $0=$ patent vessel.

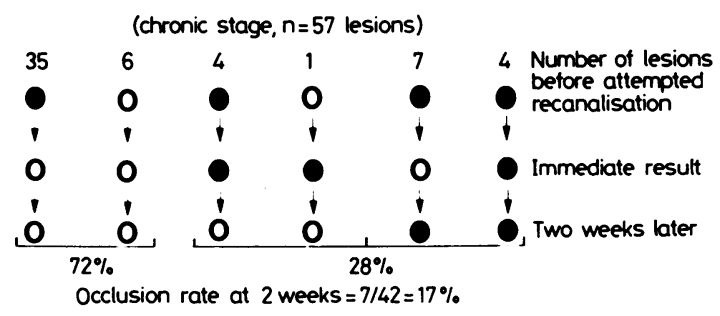

Fig. 3 Infarct related vessel patency at the chronic stage (two weeks after attempted thrombolysis) in 57 patients. $\bullet=$ occluded vessel; $0=$ patent vessel.

enzymes: two of them were restudied angiographically and in one patient the infarct related vessel had reoccluded. Finally, four lesions which had remained occluded at the acute stage were still occluded at the chronic stage.

\section{QUANTITATIVE ANGIOGRAPHIC ANALYSIS}

The individual data of the quantitative analysis of 75 stenotic lesions are given in Fig. 4. Three lesions could not be analysed because of the poor quality of the angiograms. Each depicted value represents the average value of measurements obtained in different angiographic projections. The median value for the reference diameter is $2.98 \mathrm{~mm}$ whereas the 10 th and 90th centiles are $2.22 \mathrm{~mm}$ and $4.20 \mathrm{~mm}$, respectively; the median value for the minimal obstruction diameter is $1.32 \mathrm{~mm}$, and the values of the 10th and 90th centiles are $0.78 \mathrm{~mm}$ and $1.88 \mathrm{~mm}$, respectively. As for the length of the lesion, the median value is $9 \mathrm{~mm}$

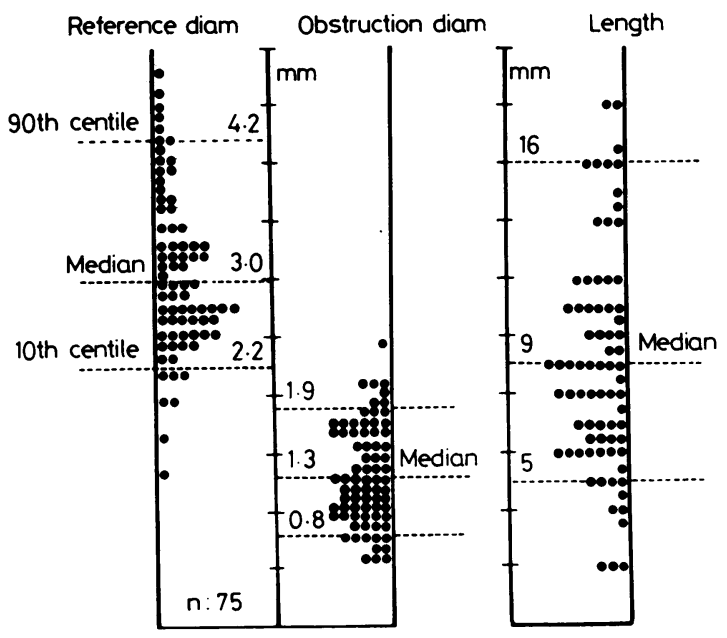

Fig. 4 Individual data for the reference and obstruction diameters as well as the length of the obstructions of 75 lesions. The dotted lines represent the 10th and 90th centiles and the median values. 
Diameter stenosis atter successtul thrombolysis $n: 75$

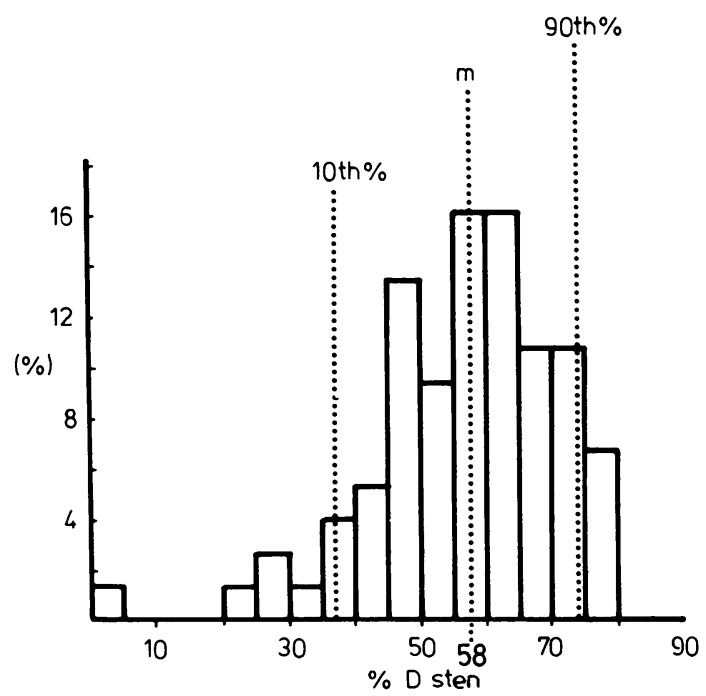

Fig. 5 Histogram (in percentage distribution) of the percentage diameter stenosis measured on 75 lesions after successful thrombolysis. The median value and the 10th and 90th centiles are given.

while values of the 10th and 90th centiles are 5 and $16 \mathrm{~mm}$, respectively. Fig. 5 is a histogram of the percentage diameter stenosis measured on 75 stenotic lesions after the successful thrombolysis. At the acute stage, the median value for the percentage diameter stenosis is $58 \%$ in this group of 75 patients; the values of the 10th and 90 th centiles are $37 \%$ and $74 \%$, respectively. A percentage diameter stenosis less than $50 \%$ is measured in $31 \%$ of the patients, whereas a diameter stenosis greater or equal to $70 \%$ is seen only in $19 \%$. When comparing the percentage diameter stenosis in a subgroup of 26 individual lesions, analysed in identical projections in the acute and chronic stage, no significant improvement or deterioration of the recanalised lesions at the chronic stage could be demonstrated (Fig. 6).

There are, of course spectacular individual changes in diameter stenosis, but for the whole group the percentage diameter stenosis does not change significantly: $54 \pm 16 \%$ at the acute stage versus $48 \pm$ $14 \%$ at the chronic stage.

The percentage diameter stenosis of eight recanalised lesions in patients who initially underwent a successful recanalisation and subsequently sustained a reinfarction in the same myocardial territory is shown in Fig. 7. Six of eight stenotic lesions had a percentage diameter stenosis greater than or equal to $58 \%$ (the median value) immediately after thrombolysis. The second column represents 11 stenotic lesions which
D sten chronic stage (same projection) n: 26

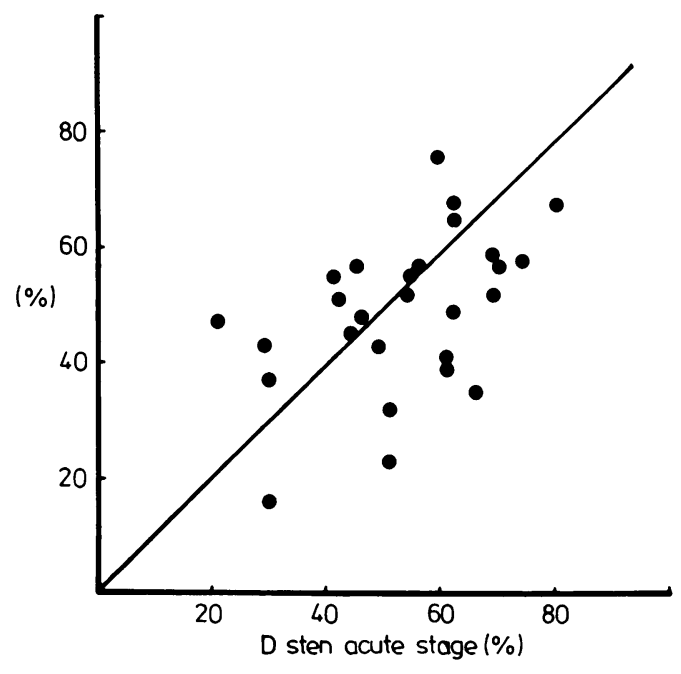

Fig. 6 Percentage diameter stenosis of 26 stenotic lesions analysed in the same projection at the acute and chronic stage.

reoccluded at the acute stage $(n=4)$ or at the chronic stage $(n=7)$ after they had been recanalised. All of them had a percentage diameter stenosis greater than or equal to $58 \%$. The diameter stenoses of 14 stenotic lesions found to be patent at the first coronary angiogram during the acute phase of their myocardial infarction are also given. Nine of them had a diameter stenosis less than $58 \%$ (median value).

From these data it appeared that reocclusion and recurrent myocardial infarction were more frequent in patients with a stenosis greater than $58 \%$ in diameter after recanalisation. The angiographic results of the combined procedure performed in 18 patients are also shown. Though the selection and decision to perform angioplasty had been based on a visual evaluation of the severity of the lesion at the time of the procedure, it appears retrospectively that 13 of the 18 lesions had a stenosis greater than $58 \%$ in diameter after thrombolysis. In these 18 patients angioplasty decreased the average percentage diameter stenosis from $59 \%$ (SD: $9.9 \%$ ) to $30 \%$ (SD: $9.9 \%$ ) and the minimal obstruction diameter increased from $1.3 \mathrm{~mm}(\mathrm{SD}: 0.4 \mathrm{~mm}$ ) to 2.2 $\mathrm{mm}$ (SD: $0.3 \mathrm{~mm}$ ). This reduction in diameter stenosis was highly significant $(p<0.0001)$ and was associated with a significant decrease in mean pressure gradient from $41 \mathrm{mmHg}$ (SD: $17 \mathrm{mmHg}$ ) to $8 \mathrm{mmHg}$ (SD: $5 \mathrm{mmHg}$ ) (Fig.8). On the basis of the changes in pressure gradient, dilatation had not been necessary in two of these patients.

Fifteen out of the 18 patients who underwent percutaneous transluminal coronary angioplasty were 


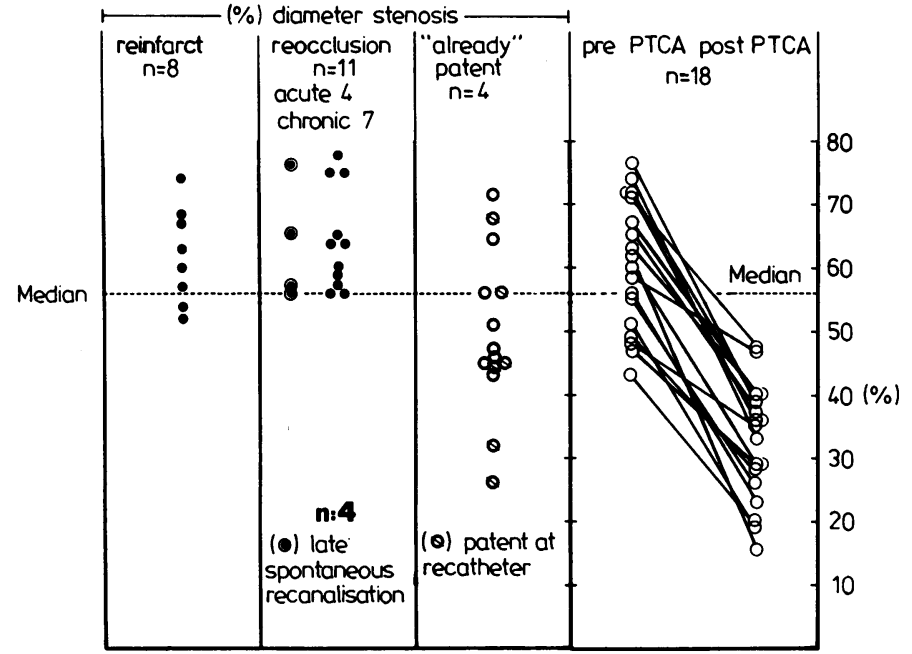

Fig. 7 Percentage diameter stenosis of coronary lesions in a subset of patients with reinfarction, reocclusion, late "spontaneous recanalisation", or with "already" patent infarct related vessels. In the last column the changes in percentage diameter stenosis after percutaneous transluminal coronary angioplasty are given.

restudied angiographically after a mean follow up of four months (range from 10 days to 11 months). In all but one the dilated vessel was patent. One patient developed exertional angina three months later. A restenosis at the site of the previous occlusion was successfully dilated a second time.

\section{Discussion}

In this paper it is shown that intracoronary streptokinase infusion and percutaneous transluminal coronary angioplasty can be carried out in the same session in an effort to enhance reperfusion. The issue, however, is not whether these combined interventions can be performed safely in the setting of acute infarction, but rather whether one is justified in doing so.
The present work is a tentative answer to this question and its conclusions are based on the results of quantitative angiographic analysis of recanalised vessels.

Since at the end of the procedure, $31 \%$ of our patients had a recanalised vessel with percentage diameter stenosis below $50 \%$, whereas a diameter stenosis greater than $50 \%$ was seen in the remainder, we had no evidence of a major residual thrombus at the site of the stenosis. No retention of contrast medium or staining of a distal thrombus was seen, so residual clot, reported by others, ${ }^{16-18}$ appears unlikely as well. Furthermore it has been the custom to continue the streptokinase treatment for about $\mathbf{3 0}$ minutes after patency has already been established.

(\%) Diameter stenosis versus Mean pressure gradient

$n: 18$, mean \pm SD

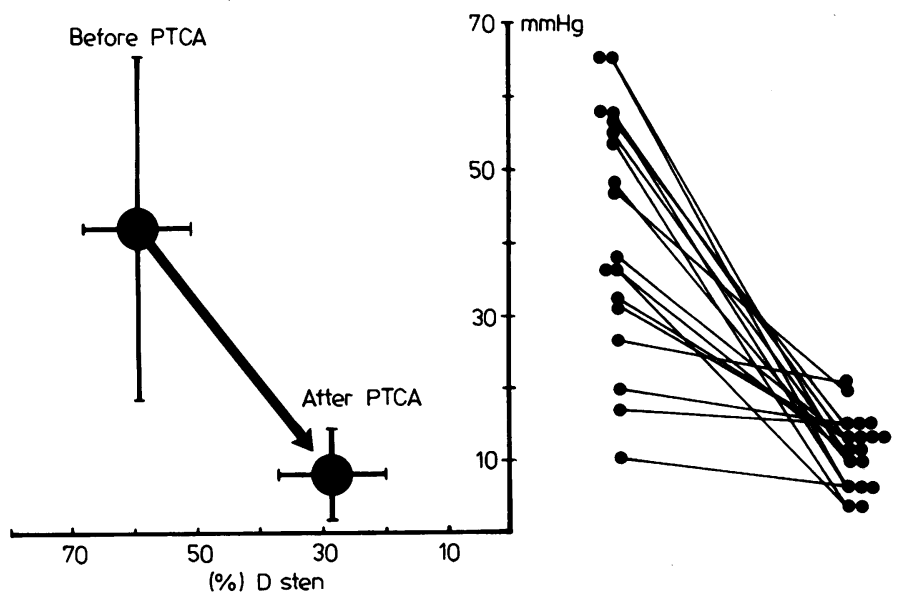

Fig. 8 Relation between the percentage diameter stenosis and the mean pressure gradient before and after percutaneous transluminal coronary angioplasty. 
On the other hand, severe residual stenosis of the recanalised vessel has been reported by other groups. ${ }^{1019}$ Their reports are based on visual and therefore subjective interpretation of the stenotic lesions. Overestimation and excessive variations by intra- or interobserver error have been reported. ${ }^{20} 21$ These discrepancies led us to evaluate the exact condition of the stenotic lesions after successful lysis by an objective, computer aided, interpretation. This method has been validated not only with copper and perspex models filled with contrast medium but also from necropsy studies. ${ }^{22-24}$

In 14 cases with clear clinical, electrocardiographic, and enzymatic signs of an acute infarction, the diseased vessel was patent at the time of coronary angiography. In these patients long lasting vasospasm superimposed on organic lesions may have led to transient occlusion and myocardial infarction. ${ }^{25} 26$ Another possibility is that the clot had already lysed in the meantime. In nine out of these 14 patients, the infarct related vessel had a mild stenotic lesion, a factor that might have facilitated the reopening of the vessel. This is the more likely as these patients were started on an intravenous perfusion of glyceryl trinitrate before intracoronary lysis was attempted. In patients with transmural acute myocardial infarction and coronary arterial thrombi, histological sections of coronary arteries have been shown to be narrowed by the atherosclerotic plaque alone from 33 to $98 \%$ (mean $81 \%$ ) at the site of the thrombus. ${ }^{27}$ When histological cross-sectional areas are compared with crosssectional areas derived from diameter measurements, our quantitative angiographic results in vivo are consistent with the histological findings. Furthermore, it is remarkable how closely the obstruction diameters after successful thrombolysis correspond with the postmortem findings reported by Fulton, ${ }^{28}$ as shown in Fig. 9. In one third of our patients the myocardial infarction had occurred when the relevant artery showed a stenosis of less than $50 \%$. Gertz et al. ${ }^{29}$ have shown experimentally that endothelial damage and thrombus formation may occur at the site of focal arterial constriction even when the reduction in luminal diameter by itself is insufficient to alter significantly the rate of flow.

As shown by Fulton ${ }^{28}$ in his elegant study on the morphology of coronary thrombotic occlusions, atherosclerotic lesions are usually of a complex nature. In two thirds of his cases, a break or a tear in the luminal lining exposed blood flowing to the material composing the underlying lesion. He postulated that this was the probable cause of platelet aggregation and fibrin deposition. ${ }^{30} 31$ In half of his cases, a haemorrhagic dissection was found which resulted in an apparent reduction of the lumen. Successful thrombolysis could again expose the material of the atheromatous lesion to flowing blood.

Whether the thrombogenic activity of this material would be as active as it was in the first instance remains speculative but secondary thrombotic occlusion may occur. Accordingly, there are strong theoretical reasons for adopting antithrombotic measures after successful thrombolysis. On the other hand, instrumental dilation of the coronary artery stenosis underlying the occlusive thrombus might produce desquamation of endothelium and shearing of the superficial portion of endothelial plaque, possibly altering its thrombogenic propensity. Subsequent fibrosis and healing ${ }^{32}$ appear to cause further enlargement of the lumen and thereby may improve local rheology. Thus, arguably, it might be advisable to perform angioplasty even in patients with a stenosis of less than $50 \%$.

Reported rates of reocclusion vary between less than $10 \%{ }^{33}$ to $25 \% .{ }^{34}$ In this study two weeks after thrombolysis, the reocclusion rate was $17 \%$. Moreover, during follow up, eight patients sustained reinfarction in the same myocardial region, so that reocclusion and/or reinfarction might affect $25 \%$ of our patients who had undergone a successful recanalisation. Thus it seems rational at the acute stage to dilate recanalised arteries with a residual stenosis greater than $58 \%$ since these stenotic lesions are liable to early reocclusion. This concept was supported by our

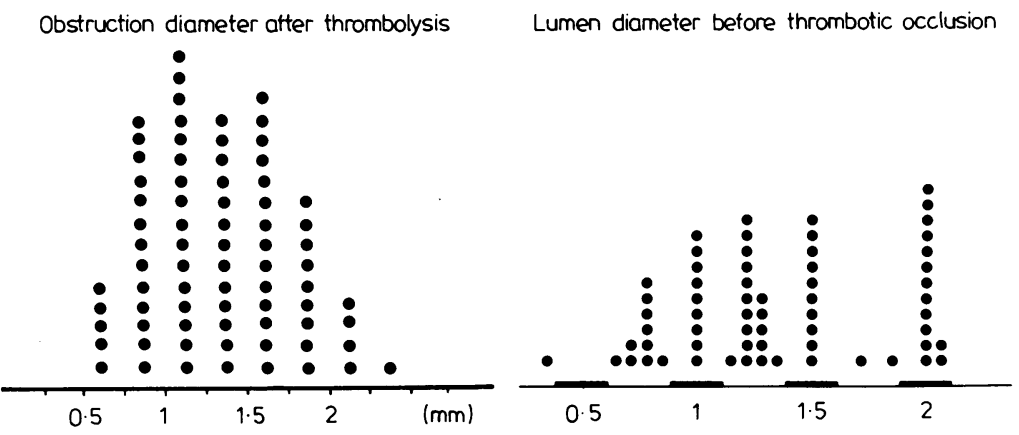

Fig. 9 Lumen diameter "before thrombotic occlusion" in 63 patients with fatal infarct (modified with permission from $F$ ulton ${ }^{28}$ ) compared with our in vivo angiographic measurement of obstruction diameter after thrombolysis. 
observations that during streptokinase infusion, recocclusion occurred in four patients (Fig. 7) despite intravenous or intracoronary administration of glyceryl trinitrate or nifedipine. Here percutaneous transluminal coronary angioplasty might have been the only way to restore blood flow adequately and to prevent immediate reocclusion. As emphasised by Meyer et al. ${ }^{11}$ the advantages of the combined procedure are savings in time and money. The same introducing sheath can be used, the catheterisation laboratory equipment and the personnel have to be used only once, and it appears to be less exacting for the patient. To date no reocclusions have occured during such immediate dilation of the critical stenosis. Fifteen out of the 18 patients who underwent percutaneous transluminal coronary angioplasty were restudied angiographically after a median follow up of four months (range from 10 days to 11 months). In all but one patient, the dilated vessel has remained patent. All 17 patients have been followed at the outpatient clinic at three month intervals. The mean period of follow up has been seven months and the longest one year. None of these patients has sustained a reinfarction thus far.

These observations indicate that percutaneous transluminal coronary angioplasty immediately after thrombolysis is a safe and reasonable procedure when after lysis of the obstruction a $58 \%$ stenosis is still present. This combined approach seems to result in a lower rate of reocclusion or reinfarction than thrombolysis alone. As further randomised trials are necessary to show the ultimate benefit of thrombolysis in acute myocardial infarction, it is recommended that during them the additional value of immediate percutaneous transluminal coronary angioplasty is investigated.

\section{References}

1 Boucek RJ, Murphy WP Jr. Segmental perfusion of the coronary arteries with fibrinolysin in man following a myocardial infarction. Am $\mathcal{F}$ Cardiol 1960; 6: 525-33.

2 Chazov EI, Matveeva LS, Mazaev AV, Sargin KE, Sadovshaya BK, Ruda Y. Intracoronary administration of fibrinolysin in acute myocardial infarct. [Eng. Abstract) Ter Arkh 1976; 48: 8-19.

3 Rentrop P, Blanke H, Karsch KR, et al. Acute myocardial infarction: intra-coronary application of nitroglycerine and streptokinase. Clin Cardiol 1979; 2: 354 63.

4 Serruys PW, Van den Brand M, Hooghoudt TEH, et al. Coronary recanalisation in acute myocardial infarction: immediate results and potential risks. Eur Heart $\mathcal{F}$ 1982; 3: 404-15.

5 Hooghoudt TEH, Serruys PW, Reiber JHC, Slager CJ, Van den Brand M, Hugenholtz PG. The effect of recanalisation of the occluded coronary artery in acute myocar- dial infarction on left ventricular function. Eur Heart $\mathcal{F}$ 1982; 3: 416-21.

6 Khaja F, Lo E, Osterberger L, O'Neil W, et al. Intracoronary fibrinolytic therapy in acute myocardial infarction: preliminary report of a randomized trial [Abstract]. Am ₹ Cardiol 1982; 49: 961.

7 Meltzer RS, Van den Brand M, Serruys PW, Fioretti P, Hugenholtz PG. Sequential intracoronary streptokinase and transluminal angioplasty in unstable angina with evolving myocardial infarction. Am Heart $\mathcal{F}$ 1982; 104: 1109-11.

8 Goldberg S, Urban P, Greenspon A, Berger BC, Walinsky P, Maroko P. Reperfusion in acute myocardial infarction [Abstract]. Am f Cardiol 1982; 49: 1033.

9 Hartzler GO, Rutherford BD, McConahay DR. Percutaneous coronary angioplasty with and without prior streptokinase infusion for treatment of acute myocardial infarction [Abstract]. Am $\mathcal{F}$ Cardiol 1982; 49: 1033.

10 Gold HK, Leinbach R, Palacios IF, et al. Effect of immediate angioplasty on coronary patency following infarct therapy with streptokinase [Abstract]. Am F Cardiol 1982; 49: 1033.

11 Meyer J, Merx W, Schmitz H, et al. Percutaneous transluminal coronary angioplasty immediately after intracoronary streptolysis of transmural myocardial infarction. Circulation 1982; 66: 905-13.

12 Fioretti P, Simoons ML, Serruys PW, Van den Brand M, Fels PW, Hugenholtz PG. Clinical course after attempted thrombolysis in myocardial infarction. Results of pilot studies and preliminary data from a randomised trial. Eur Heart f 1982; 5: 422-32.

13 Reiber JHC, Gerbrands JJ, Kooijman CJ, et al. Quantitative coronary angiography with automated contour detection and densitometry; technical aspects. In: Just H, Heintzen PH, eds. Angiocardiography, current status and future developments. Berlin Heidelberg New York: Springer-Verlag, 1983: in press.

14 Reiber JHC, Gerbrands JJ, Booman F, et al. Objective characterization of coronary obstructions from monoplane cineangiograms and three-dimensional reconstruction of an arterial segment from two orthogonal views, In: Schwartz MD, ed. Application of computers in medicine. IEEE Cat. No. TH0095-0; 1982: 93-100.

15 Kooijman CJ, Reiber JHC, Gerbrands JJ, et al. Computer-aided quantitation of the severity of coronary obstructions from single view cineangiograms. International Symposium on Medical Imaging and Image Interpretation, IEEE Cat. No. 82CH1804-4, 1982: $59-64$.

16 Hugenholtz PG, Rentrop P. Thrombolytic therapy for acute myocardial infarction: quo vadis? A review of the recent literature. Eur Heart $\mathcal{f}$ 1982; 3: 395-403.

17 Rentrop KP, Blanke H, Karsche KR, Rahlf G, Leitz K. Infarktgrössenbegrenzung durch nicht-chirurgische Rekanalisation der Koronararterien. Dtsch Med Wochenschr 1981; 106: 765-70.

18 Gangadharan V, Ramos RG, Hauser AM, Westveer DC, Timmis GC, Gordon S. Intracoronary streptokinase: evidence for continued iatrogenic or spontaneous thrombolysis after termination of infusion [Abstract]. Am $\mathcal{F}$ Cardiol 1982; 49: 973.

19 Rutsch W, Schartl M, Mathey D, et al. Percutaneous 
transluminal coronary recanalization: procedure, results, and acute complications. Am Heart $\mathcal{F}$ 1981; 102: 117881.

20 Zir LM, Miller SW, Dinsmore RE, Gilbert JP, Harthorne JW. Interobserver variability in coronary angiography. Circulation 1976; 53: 627-32.

21 Detre KM, Wright E, Murphy ML, Takaro T. Observer agreement in evaluating coronary angiograms. Circulation 1975; 52: 979-86.

22 Cherrier F, Booman F, Serruys PW, Cuillière M, Danchin N, Reiber JHC. L'angiographie coronaire quantitative. Application à l'évaluation des angioplasties transluminales coronaires. Arch Mal Coeur 1981; 74: 1377-87.

23 Gerbrands JJ, Reiber JHC, Booman F. Computer processing and classification of coronary occlusions. In: Gelsema ES, Kanal LV, eds. Pattern recognition in practice. New York: North-Holland Publishing Company, 1980: 223-33.

24 Serruys PW, Booman, Troost GJ, et al. Computerised quantitative coronary angiography applied to the PTCA-procedure; advantages and limitations. In: Kaltenbach M, et al., eds. Transluminal coronary angioplasty and intracoronary thrombolysis. Coronary heart disease IV. Berlin, Heidelberg, New York: Springer Verlag, 1982: 110-24.

25 Oliva PB, Breckinridge JC. Arteriographic evidence of coronary arterial spasm in acute myocardial infarction. Circulation 1977; 56: 366-74.

26 Maseri A, L'Abbate A, Baroldi G, et al. Coronary vasospasm as a possible cause of myocardial infarction: a conclusion derived from the study of "preinfarction" angina. N Engl I Med 1978; 299: 1271-7.

27 Brosius FC III, Roberts WC. Significance of coronary aterial thrombus in transmural acute myocardial infarction. A study of 54 necropsy patients. Circulation 1981; 63: $810-6$.
28 Fulton WFM. The morphology of coronary thrombotic occlusions relevant to thrombolytic intervention. In: Kaltenbach $\mathrm{M}$, et al., eds. Transluminal coronary angioplasty and intracoronary and thrombolysis. Berlin, Heidelberg, New York: Springer-Verlag 1982: 244-52.

29 Gertz SD, Uretsky G, Wajnberg RS, Navot N, Gotsman MS. Endothelial cell damage and thrombus formation after partial arterial constriction: relevance to the role of coronary artery spasm in the pathogenesis of myocardial infarction. Circulation 1981; 63: 476-86.

30 Friedman $M$, Van den Bovenkamp GJ. The pathogenesis of a coronary thrombus. Am $\mathcal{F}$ Pathol 1966; 48: $19-44$.

31 Harland WA, Holburn AM. Coronary thrombosis and myocardial infarction. Lancet 1966; ii: 1158-60.

32 Block PC, Baughman KL, Pasternak RC, Fallon JT. Transluminal angioplasty: correlation of morphologic and angiographic findings in an experimental model. Circulation 1980; 61: 778-85.

33 Rentrop P, Blanke H, Karsch KR, Kaiser H, Köstering $H$, Leitz $K$. Selective intracoronary thrombolysis in acute myocardial infarction and unstable angina pectoris. Circulation 1981; 63: 307-17.

34 Merx W, Dörr R, Rentrop P, et al. Evaluation of the effectiveness of intracoronary streptokinase infusion in acute myocardial infarction: postprocedure management and hospital course in 204 patients. Am Heart $\mathcal{F}$ 1981; 102: 1181-7.

35 Grüntzig AR, Senning A, Siegenthaler WE. Nonoperative dilatation of coronary-artery stenosis: percutaneous transluminal coronary angioplasty. $N$ Engl f Med 1979; 301: 61-8.

Requests for reprints to Dr P W Serruys, Catheterization Laboratory, Erasmus University and University Hospital Dijkzigt, PO Box 1738, 3000 DR Rotterdam, The Netherlands. 